\title{
A insuficiência óssea na doença renal crônica: papel do paratormônio
}

Francisco José Albuquerque de-Paula'

$\mathrm{O}$ paratormônio (PTH) é um hormônio fundamental no controle da homeostase do cálcio, agindo direta ou indiretamente em órgãos relacionados ao armazenamento, à excreção e à absorção deste íon divalente. Discreta queda dos níveis circulantes de cálcio, 10\%, é suficiente para aumentar a secreção de PTH em 200\% a 300\% (1,2).

Na última década, a imagem do PTH como hormônio com ação exclusivamente catabólica sobre o tecido ósseo mudou radicalmente, estando claro que este pode promover tanto formação quanto ressorção óssea. O hiperparatireoidismo primário clássico e o hiperparatireoismo secundário da insuficiência renal crônica (IRC) são dois exemplos tradicionais que indicam que a exposição óssea a níveis constantemente elevados de PTH favorece o catabolismo ósseo. Na presente edição dos ABEM, Vieira e cols. (3) mostram dados interessantes sobre a dramática alteração de funcionamento da paratireoide na IRC. Por outro lado, a exposição óssea a níveis elevados de forma intermitente de PTH favorece o anabolismo. Desde o início desta década, o PTH passou a ser uma opção importante para o tratamento da osteoporose, na realidade a única disponível como estimulante da formação óssea, enquanto as demais classes de drogas são inibidoras da ressorção óssea. Diversos grupos de pesquisa têm se dedicado a elucidação da ação biológica desse peptídeo em nível tecidual.

A remodelação óssea que corresponde ao processo de renovação do esqueleto ocorre nas unidades ósseas multicelulares, onde pequenas porções de osso velho são retiradas pelos osteoclastos e posteriormente repostas por osteoblastos. A atividade de remodelação óssea sofre influência de fatores genéticos, ambientais e hormonais e, quando em condições favoráveis, há equilíbrio entre ressorção e formação.

Diversas evidências sugerem que o efeito anabólico do PTH depende não só de sua ação direta sobre osteoblastos e precursores, como também da participação de fatores de crescimento como o IGF-I. O estímulo de formação envolve incremento de diferenciação de precursores de osteoblastos, proliferação e ação antiapoptótica de osteoblastos. Em parte, esses efeitos dependem do aumento de expressão do fator de transcrição Runx2, um elemento-chave no processo de diferenciação de osteoblastos.

Enquanto isso a elevação mantida de PTH estimula osteoblastos a produzir RANKL e MCP-1, fatores estimuladores da osteoclastogênese e da atividade de ressorção óssea realizada por osteoclastos maduros.

Apesar do avanço no conhecimento de mecanismos moleculares da ação do PTH, ainda não se tem claro quais são os fatores primordiais na determinação do efeito catabólico ou anabólico ósseo desse hormônio. Também ainda não se tem claro qual o papel fisiológico do PTH no processo de desenvolvimento de massa óssea na infância e puberdade nem durante a fase de declínio de massa óssea na pós-menopausa e no envelhecimento (4).

${ }^{1}$ Professor doutor do Departamento de Clínica Médica, Faculdade de Medicina de Ribeirão Preto, Universidade de São Paulo (FMRP-USP) e Visiting Scholar, Center for Clinical and Translational Research, Maine Medical Center Research Institute

Correspondência para:

Francisco José Albuquerque de-Paula

Departamento de Clínica Médica da FMRP-USP

Av. Bandeirantes, 3.900

14049-900 - Ribeirão Preto, SP, Brasil fjpaula@fmrp.usp.br 
Outro aspecto interessante que ainda está por ser melhor compreendido é o significado fisiológico da secreção de vários fragmentos de PTH pela paratireoide, além da molécula inteira PTH (1-84). A ação biológica do PTH em seu receptor PTHIR depende da presença da fração aminoterminal 1-34, a qual nem sempre está presente entre os peptídeos sintetizados pelas paratireoides. Os ensaios de PTH de segunda geração, PTH intacto (iPTH), ainda reconhecem a fração 7-84 do PTH. Esses ensaios, desenvolvidos na década de 1980 , ainda são os mais utilizados na prática clínica atual. Diversas evidências indicam que o fragmento PTH (7-84) contrapõe-se à ação de ressorção óssea do PTH (1-84). Portanto, é possível que a influência do PTH sobre o tecido ósseo seja mais bem avaliada considerando-se não a concentração absoluta dos níveis de $\mathrm{PTH}$, mas as concentrações dos diversos peptídeos com capacidade de influenciar a ação óssea desse hormônio. Esse problema torna-se particularmente importante na IRC, situação em que a secreção de PTH (7-84), bem como de outras frações que podem não ser reconhecidas pelo iPTH, aumenta significativamente. Além disso, a medida das taxas de PTH circulante é utilizada como parâmetro de definição terapêutica da doença óssea na IRC (osteodistrofia renal).

Mais recentemente, surgiram os ensaios de PTH de terceira geração, os quais devem reconhecer apenas $\mathrm{O}$ hormônio biologicamente ativo, sinalizando a possibilidade de avanço na avaliação do hiperparatireoidismo secundário da IRC. No entanto, os resultados obtidos em quatro estudos anteriores são contraditórios quanto ao benefício da determinação da relação PTH (1/84)/ PTH (7-84) para discriminação de osteodistrofia renal (5). Apenas um estudo sugeriu vantagem na utilização dos dois métodos de dosagem de PTH em relação à dosagem isolada de iPTH ou PTH bioativo.

No estudo apresentado por Vieira e cols. (3), utilizou-se um ensaio imunofluorimétrico capaz de reconhecer um amplo espectro de formas de $\mathrm{PTH}$, as quais são truncadas da fração aminoterminal, em soro de pacientes com IRC em estágio terminal. As amostras foram utilizadas ainda para determinação de $\mathrm{iPTH}$, ensaio de segunda geração, e foram também submetidas à cromatografia de gel de filtração em coluna e o conteúdo de PTH nos tubos de eluato foi medido utilizando-se os dois ensaios. Os resultados mostraram que pacientes com hiperparatireoidismo secundário a IRC apresentam um amplo espectro de formas circulantes de PTH, as quais não são reconhecidas nos ensaios de iPTH, frequentemente utilizados na prática clínica.

Os resultados são encorajadores quanto à necessidade de realizar outros estudos em que se correlacione a presença desses fragmentos de PTH com parâmetros de atividade de remodelação óssea, seja por biópsia óssea, marcadores bioquímicos de remodelação óssea ou mesmo técnicas mais precisas de quantificação óssea por radiografia como microCT quantitativo.

Agradecimentos: Francisco José Albuquerque de Paula recebe suporte financeiro do Conselho Nacional de Desenvolvimento Científico e Tecnológico (CNPq), Programa PDE, processo: 201650/2008-8.

Declaração: o autor declara não haver conflitos de interesse científico neste estudo.

\section{REFERÊNCIAS}

1. Paula FJ, Lanna CM, ShuhamaT, Foss MC. Effect of metabolic control on parathyroid hormone secretion in diabetic patients. Braz $\mathrm{J}$ Med Biol Res. 2001;34(9):1139-45.

2. Lanna CM, Paula FJ, Montenegro Jr RM, Moreira AC, Foss MC. Parathyroid hormone secretion in chronic human endogenous hypercortisolism. Braz J Med Biol Res. 2002;35(2):229-36.

3. Vieira JG, Kunii IS, Ohe MN, Carvalho AB. Heterogeneity of carboxyl-terminal parathyroid hormone (PTH) circulating forms in patients with hyperparathyroidism due to end stage renal disease. Arq Bras Endocrinol Metab [no prelo].

4. Pereira LC, Pereira FA, Sá MF, Foss MC, de Paula FJ. Parathyroid hormone secretion in women in late menopause submitted to EDTA-induced hypocalcemia. Maturitas. 2008;59(1):91-4.

5. Souberbielle JC, Roth H, Fouque DP. Parathyroid hormone measurement in CKD. Kidney Int. 2009 [no prelo]. 